\title{
Systemic thromboembolism leading to myocardial infarction and stroke after fenestrated total cavopulmonary connection
}

\author{
D G Wilson, J D Wisheart, A G Stuart
}

\begin{abstract}
Thromboembolic phenomena involving the caval veins, right atrium, and pulmonary artery are recognised complications after the Fontan operation and other forms of total cavopulmonary connection. A rare case of systemic thromboembolism is reported in a 3 year old girl who had repeated coronary and cerebral thromboembolic events after a fenestrated total cavopulmonary shunt operation. A survey of the 18 paediatric cardiac units in the United Kingdom and Ireland showed a wide discrepancy in anticoagulation policies after Fontantype operations. Prevention of thrombotic complications by lifelong postoperative anticoagulation may outweigh the risk of haemorrhage.
\end{abstract}

(Br Heart f 1995;73:483-485)

Congenital Heart

Disease Research

Unit, University

Hospital of Wales,

Heath Park, Cardiff

$D$ G Wilson

A G Stuart

Bristol Royal Hospital for Sick Children, St Michael's Hill, Bristol $\mathrm{J} D$ Wisheart

Correspondence to: Dr A G Stuart, University Hospital of Wales, Heath Park, Cardiff CF4 4XW. Accepted for publication 25 October 1994
Keywords: systemic thromboembolism; fenestrated

The Fontan operation was first described in the treatment of tricuspid atresia, ${ }^{1}$ but modifications are now used to palliate a variety of heart defects in which there is an absent or hypoplastic ventricle. Factors predisposing to postoperative complications such as thrombosis include increased pulmonary vascular resistance and ventricular dysfunction. ${ }^{23}$ Outcome in high risk patients is improved if total cavopulmonary shunt; anticoagulation treatment.

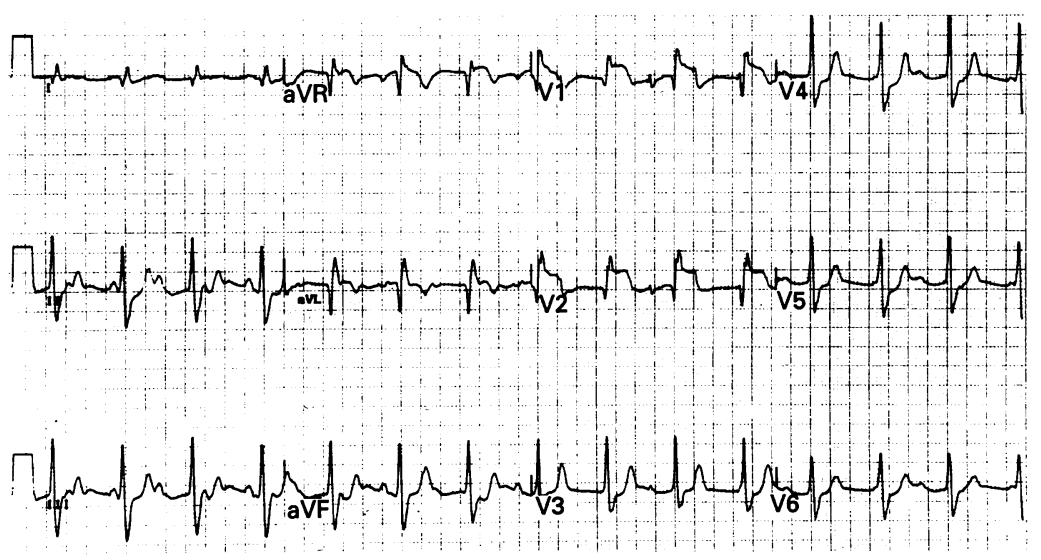

Figure 1 Twelve lead electrocardiogram demonstrating complete heart block and ST segment elevation in leads V1 and V2.

an interatrial communication (fenestration) is created, allowing off loading of the cavopulmonary circulation at the expense of increased cyanosis. ${ }^{45}$ The fenestration may be closed at a later date if the haemodynamics are favourable.

\section{Case report}

A 3 year old girl presented with repeated systemic thromboembolism after undergoing a fenestrated total cavopulmonary connection. As a neonate she presented with cyanosis and cardiac failure due to right atrioventricular valve atresia, ventriculoarterial discordance, and coarctation of the aorta. At 1 month of age she underwent coarctectomy and pulmonary artery banding. At cardiac catheterisation aged 16 months the total pulmonary vascular resistance was 3.4 units $/ \mathrm{m}^{2}$ and the arteriolar vascular resistance was $1 \mathrm{unit} / \mathrm{m}^{2}$. Fourteen months later she underwent debanding of the pulmonary artery, reconstruction of the right pulmonary artery with pericardium, and total cavopulmonary connection with a Gore-tex (W L Gore and Associates, Arizona) intra-atrial baffle. A 4.5 $\mathrm{mm}$ fenestration was created in the baffle because the pulmonary artery had been reconstructed. The child made a good recovery but mild cyanosis remained suggesting right to left flow through the fenestration. She was anticoagulated with warfarin for 3 months after surgery.

Transient unilateral facial weakness developed 7 months after the operation. Although intracardiac thrombus was not visualised on transthoracic echocardiography, thromboembolism was suspected and treatment with low dose aspirin was started. Two months later she was admitted to her local hospital with disorientation, chest pain, and increased cyanosis. An infection was suspected and antibiotics were started. She was discharged after 3 days but was readmitted to the regional paediatric cardiac unit the following day with persisting lethargy and breathlessness. Retrospective analysis of the original admission electrocardiogram showed complete heart block and ST segment elevation in leads V1 and V2 (fig 1). Serum cardiac enzymes were increased (aspartate transaminase $867 \mathrm{IU} / 1$, creatine kinase $341 \mathrm{IU} / 1$, and $\beta$ hydroxbutyrate 417 IU/1), compatible with myocardial infarction. Further investigation 
Figure 2 (A) Angiogram showing a filling defect with the appearances of thrombus in the main stem of the left coronary artery. The left anterior descending branch does not fill with contrast on this frame, but subsequent frames demonstrated partial occlusion. (B) Diagrammatic representation of the main points seen in $(A)$.
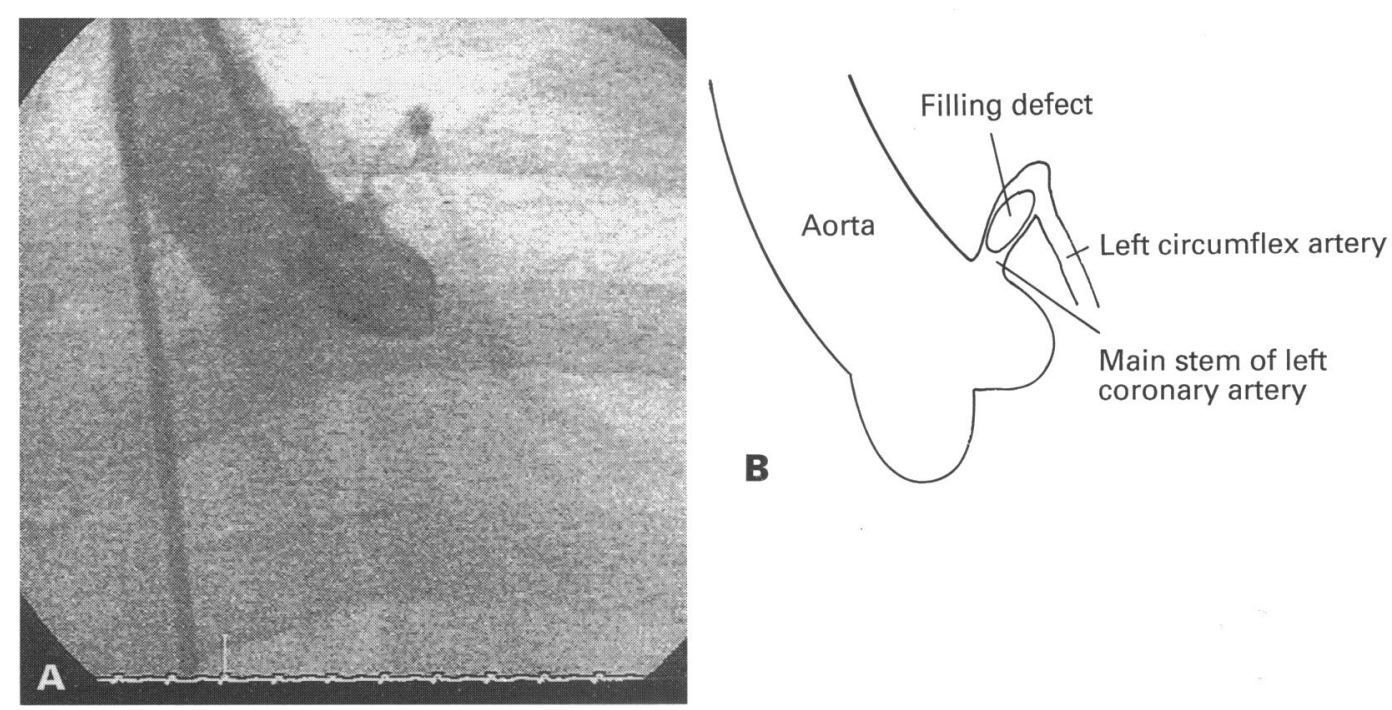

by transoesophageal echocardiography confirmed left ventricular dysfunction with apical hypokinesia. Intracardiac thrombus was not visualised, but there was spontaneous contrast formation in the right atrium and considerable right to left flow across the fenestration. At cardiac catheterisation she had bilateral femoral vein and inferior vena caval thrombosis. An aortogram showed partial thrombotic occlusion of the left mainstem and left anterior descending coronary artery (fig 2). There was ventricular dysfunction (cardiac output $2.4 \mathrm{l} / \mathrm{min} / \mathrm{m}^{2}$ ) and increased left ventricular end diastolic pressure $(18-20 \mathrm{~mm} \mathrm{Hg})$. Catheterisation of the cavopulmonary shunt revealed mean pressures of $17-19 \mathrm{~mm} \mathrm{Hg}$ and a calculated pulmonary vascular resistance of 12 units $/ \mathrm{m}^{2}$ (arteriolar pulmonary vascular resistance $3 \cdot 3$ units $/ \mathrm{m}^{2}$ ). Pulmonary angiography showed minor narrowing of the proximal left pulmonary artery with no evidence of pulmonary emboli.

After cardiac catheterisation she was anticoagulated with warfarin (international normalised ratio $3-4.5$ ) and aspirin was discontinued. Three months later she presented with further facial weakness which evolved into a left hemiparesis. A computer assisted tomographic headscan revealed multiple areas of infarction. Serum antithrombin III activity was $59 \%$ of the control value (paediatric reference range $80-139 \%$ ). Follow up electrocardiography showed first degree heart block and resolution of the ST segment changes. Low dose aspirin was added to her warfarin treatment and her motor function and exercise tolerance improved. Repeat cardiac catheterisation six months after myocardial infarction showed improved cardiac output $\left(5 \mathrm{l} / \mathrm{min} / \mathrm{m}^{2}\right)$ and left ventricular end diastolic pressure $(13 \mathrm{~mm} \mathrm{Hg}$ ), but pulmonary vascular resistance remained increased (total pulmonary vascular resistance 10 units $/ \mathrm{m}^{2}$, arteriolar pulmonary vascular resistance 5 units $/ \mathrm{m}^{2}$ ). The left anterior descending coronary artery was completely occluded. The child currently remains with moderate cyanosis and reduced exercise tolerance, and has been accepted for heart-lung transplantation.

\section{Discussion}

Right atrial and caval thrombosis can occur after Fontan-type operations and may result in pulmonary embolism or death. ${ }^{267}$ Neurological events have also been described after total cavopulmonary connection, ${ }^{89}$ but this is the first report of embolism to the coronary circulation. Factors predisposing to thrombogenesis have been recently reviewed by Hedrick et $a l^{10}$ and include: (i) sluggish blood flow through the caval veins and right atrial baffle; (ii) abnormal surfaces exposed to blood, for example the prosthetic intra-atrial baffle; and (iii) changes in blood composition favouring thrombus formation. Acquired protein $\mathrm{C}$ deficiency, reduced concentration of antithrombin III, and increased von Willebrand factor activity have been described after Fontan operations ${ }^{811}$ but a causal association with clinically significant thrombosis has yet to be established.

This child has several risk factors for thrombosis including an extensive Gore-tex baffle, sluggish right heart blood flow (suggested by spontaneous contrast formation on echocardiography), and a reduced antithrombin III activity. Further assessment of coagulation factors has not been undertaken, as this would require discontinuing warfarin treatment for up to 2 weeks. Levels of parental antithrombin III, protein C, and protein S are normal, excluding most familial causes of thrombosis.

Systemic thromboembolism was probably caused by passage of emboli from right to left through the interatrial fenestration. Although an intracardiac clot was not seen, inferior vena cava thrombosis demonstrated at cardiac catheterisation may have been a source of emboli. Possibly thrombus developed on the left atrial surface of the Gore-tex patch, but the thrombogenic potential of the two surfaces is identical (W L Gore and Associates, personal communication) and this is unlikely.

The optimum anticoagulation policy after Fontan-type operations is unclear. Anticoagulation with warfarin for 6-12 weeks followed by aspirin treatment is recommended, ${ }^{12}$ but the indications for lifelong anticoagulation are unknown. The risk of haemorrhage in 
Antithrombotic policy after Fontan operation or its modification in paediatric cardiac units in the United Kingdom and Ireland*

\begin{tabular}{ll}
\hline Type of antithrombotic treatment & No \\
\hline Warfarin for 3 months or less & $1(8)$ \\
Warfarin for 3 months followed by long-term aspirin & $2(17)$ \\
Warfarin for 3-6 months & $1(8)$ \\
Warfarin plus aspirin for 6 months & $1(8)$ \\
Lifelong anticoagulation with warfarin & $6(50)$ \\
Long-term aspirin & $1(8)$ \\
\hline
\end{tabular}

Values in parentheses are percentages. ${ }^{\star} \mathrm{Six}$ units did not have a specific protocol for anticoagulation (see text).

adults and children on long-term oral anticoagulation medication is regarded as acceptably low. ${ }^{1314}$ There is a lack of prospective data, however, showing the safety of longterm anticoagulation in childhood. The efficacy of aspirin in preventing thrombosis after Fontan-type operations is not established, but recent overviews have highlighted the role of aspirin in maintaining the patency of surgical shunts and preventing pulmonary embolism. ${ }^{15-17}$ Moreover, addition of low dose aspirin to warfarin treatment after heart valve replacement has been shown to reduce thromboembolic events with no significant increase in major haemorrhage. ${ }^{18}$

We conducted a telephone survey of the 18 paediatric cardiac units in the United Kingdom and Ireland to establish the approach to antithrombotic treatment for patients undergoing Fontan-type operations. In 12 units $(67 \%)$ there was an identifiable protocol (table), but in six (33\%) practice was determined by consultant preference or individual haemodynamics. Ten units (56\%) reported awareness of patients with serious thrombotic complications, including two units where warfarin is not used routinely.

We report a child who suffered significant morbidity due to systemic thromboembolism after a fenestrated total cavopulmonary shunt operation. There is a marked variation in anticoagulation policies after Fontan-type operations in the United Kingdom and Ireland. Although it may be safe to discontinue anticoagulation in some patients, the optimal timing of this is unknown. Lifelong anticoagulation may reduce morbidity and mortality after the operation, but the risk of severe haemorrhage cannot be ignored. A multicentre trial is needed to determine the safest antithrombotic policy after Fontan-type operations.

1 Fontan F, Baudet E. Surgical repair of tricuspid atresia. Thorax 1971;26:240-8

2 Kirklin JK, Blackstone EH, Kirklin JW, Pacifico AD, Bargeron LM. The Fontan operation: ventricular hypertrophy, age and date of operation as risk factors. $\mathcal{F}$ Thorac Cardiovasc Surg 1986;92:1049-64.

3 Coles JG, Kielmanowicz S, Freedom RM, Benson LN, Moes F, Olley PM, et al. Surgical experience with the modified Fontan procedure. Circulation 1987;76(suppl III):61-6.

4 Laks H, Haas GS, Pearl JM, Sadeghi AM, George B, Santulli TV, et al. The use of an adjustable intraatrial communication in patients undergoing the Fontan and definitive heart procedures. Circulation 1988;76(suppl II):357.

5 Bridges ND, Lock JE, Castaneda AR. Baffle fenestration with subsequent transcatheter closure. Circulation 1990; 82:1681-9.

6 DeLeon SY, Koopot R, Mair DD, Idriss FS, Ilbawi MN, Muster AJ, et al. Surgical management of occluded conduits after the Fontan operation in patients with Glenn duits after the Fontan operation in patients with
shunts. $\mathcal{F}$ Thorac Cardiovasc Surg 1984;88:601-5.

7 Dobell ARC, Trusler GA, Smallhorn JF, Williams WG. Atrial thrombi after the Fontan operation. Ann Thorac Surg 1986;42:664-7.

8 Cromme-Dijkhuis AH, Henkens CMA, Bijleveld CMA, Hillege HL, Bom VJJ, van der Meer J. Coagulation factor abnormalities as possible risk factors after Fontan operations. Lancet 1990;336:1087-90.

9 Fyffe DA, Kline CH, Sade RM, Gillette PC. Transoesophageal echocardiography detects thrombus formation not identified by transthoracic echocardiography after the Fontan operation. $\mathcal{F}$ Am Coll Cardiol 1991; 18:1733-7.

10 Hedrick M, Elkins RC, Knott-Craig CJ, Razook JD. Successful thrombectomy for thrombosis of the right side of the heart after the Fontan operation. $\mathcal{F}$ Thorac Cardiovasc Surg 1993;105:297-301.

11 Turner-Gomes SO, Andrew M, Coles J, Trusler GA, Williams WG, Rabinovitch $M$. Abnormalities in von Willebrand factor and antithrombin III after cardiopulmonary bypass operations for congenital heart disease. monary bypass operations for congenital
$\mathcal{J}$ Thorac Cardiovasc Surg 1992;103:87-97.

12 Kirklin JW, Barratt-Boyes BG. Tricuspid atresia and the Fontan operation. In: Cardiac surgery. 2nd ed. New York: Churchill Livingstone, 1993:1055-104.

13 Forfar JC. Prediction of hemorrhage during long-term oral coumarin anticoagulation by excessive prothrombin ratio. Am Heart $\mathcal{F}$ 1982;103:445-6.

14 Evans DI, Rowlands M, Poller L. Survey of oral anticoagulant treatment in children. F Clin Pathol 1992;45:707-8.

15 Antiplatelet Trialists' Collaboration. Collaborative overview of randomised trials of antiplatelet therapy-I: prevention of death, myocardial infarction, and stroke by prolonged antiplatelet therapy in various categories of patients. $B M \mathcal{F}$ 1994;308:81-106.

16 Antiplatelet Trialists' Collaboration. Collaborative overview of randomised trials of antiplatelet therapy-II: maintenance of vascular graft or arterial patency by antiplatelet therapy. $B M F$ 1994;308:159-68.

17 Antiplatelet Trialists' Collaboration. Collaborative overview of randomised trials of antiplatelet therapyIII: reduction of venous thrombosis and pulmonary III: reduction of venous thrombosis and pulmonary medical patients. BMF 1994;308:235-46.

18 Turpie AGG, Gent M, Laupacis A, Latour Y, Gunstensen Turpie AGG, Gent M, Laupacis A, Latour Y, Gunstensen
$\mathrm{J}$, Basile F, et al. A comparison of aspirin with placebo in patients treated with warfarin after heart-valve replacepatients treated with warfarin after hear
ment. $N$ Engl F Med 1993;329:524-9. 